\title{
Dental Neglect Score and its Association with Oral Hygiene and Dental Caries among Adults visiting A Tertiary Hospital in Kathmandu
}

\author{
Dr. Rosina Bhattarai, ${ }^{1}$ Dr. Sunita Khanal, ${ }^{2}$ Dr. Sujita Shrestha, ${ }^{2}$ Dr. G. Nagaraja Rao ${ }^{2}$ \\ ${ }^{1}$ Department of Community Dentistry, College of Medical Sciences, Bharatpur, Nepal; \\ ${ }^{2}$ Department of Community Dentistry, Kantipur Dental College Teaching Hospital and Research Centre, Kathmandu, Nepal.
}

\begin{abstract}
Introduction: Dental neglect is a harmful behavior which brings many unwanted consequences in oral health. It has been found to be related to poor oral hygiene and increase in oral diseases. Dental neglect scale is a valid measure to record dental neglect among adults.

Objective: To assess dental negligence using Dental Neglect Scale (DNS) questionnaire and assess its association with oral hygiene status and dental caries.

Methods: Study consisted of convenient sample of 287 adults visiting Kantipur Dental Hospital who were given six-item Dental Neglect Scale questionnaire followed by oral examination using Oral Hygiene Index-Simplified (OHI-S) and Decayed Missing Filled Teeth (DMFT) index.

Results: The mean DNS score was found to be 18.40. Statistically significant difference was seen between age of the participants and mean DNS score (P value 0.033 ) as well as with gender and mean DNS score (P value 0.001). Association between dental neglect score and DMFT categorised and $\mathrm{OHI}-\mathrm{S}$ shows statistically significant difference the groups with $\mathrm{p}$ value 0.022 and 0.001 respectively.

Conclusion: Dental neglect was found to be high among adults in Kathmandu and caries and oral hygiene status were significantly associated with dental neglect. Variation in dental neglect exists in relation to various sociodemographic variables like age and gender.

Keywords: Dental neglect score; DMFT index; oral health.
\end{abstract}

\section{INTRODUCTION}

Dental neglect has been defined as behavior and attitudes which are likely to have detrimental consequences for the individual's oral health, or more specifically as failure to take precautions to maintain oral health, failure to obtain needed dental care and physical neglect of oral cavity. ${ }^{1}$ Dental neglect is playing an important role in the negative outcomes regarding oral health and the functioning among individuals altogether. ${ }^{2}$

Thomson and Locker in $2000^{3}$ had designed the Dental Neglect Scale (DNS) to be used in adults by modifying the

\section{Correspondence:}

Dr. Rosina Bhattarai

Department of Community Dentistry, College of Medical Sciences, Bharatpur, Nepal

email: rosinabhattarai@gmail.com

\section{Citation}

Bhattarai R, Khanal S, Shrestha S, Rao GN. Dental Neglect Score and its Association with Oral Hygiene and Dental Caries among Adults visiting A Tertiary Hospital in Kathmandu. J Nepal Soc Perio Oral Implantol. 2020;4(7):14-7.

DOI: https://doi.org/10.3126/jnspoi.v4i1.30898
Adelaide scale used to measure dental neglect among children based on parental response. ${ }^{4}$ It helps to assess the extent to which a person cares for his/her teeth, seeks professional dental treatment and prioritises oral health.

Assessment of dental neglect in a population helps in recognizing the disparities in dental neglect and oral health behavior. Hence this study was conducted to assess dental negligence using DNS questionnaire and assess their association with oral hygiene status and dental caries in Kathmandu to know whether dental neglect still prevails despite dental awareness and abundant resources for dental care.

\section{METHODS}

A cross-sectional study was conducted among patients and their attendants greater than 18 years of age visiting a tertiary dental hospital in Kathmandu. The study duration was from September 2019 to March 2020. The ethical approval for the study was obtained from the Institutional Review Committee of Kantipur Dental College Teaching Hospital and Research Centre. The participants were 
explained verbally regarding the objective of the study and the procedure involved followed by the written informed consent. It was ensured that the examination and treatment of the participants were not delayed or ceased due to the study. Convenience sampling technique was used for the selection of study subjects. Adults greater than 18 years of age were included in the study. Exclusion criteria included completely edentulous patients, adults who did not give consent to the study and those working in the field of healthcare.

Sample size was calculated using the formula $\mathrm{Z}^{2} \mathrm{pq} / \mathrm{e}^{2}$

\section{Z: $\quad 1.96$ for $95 \%$ confidence interval}

p: Proportion of population with DNS score $>15=$ 75.8 as no similar study had been carried out in Nepal and Indore is one of the major cities of India which is large, populated and similar to Kathmandu ${ }^{5}$

q: $1-p=24.2$

e: Maximal tolerable error $=5 \%$

So, with this formula the sample size was calculated to be 281

Taking 5\% non-response rate sample size was calculated to be 295

Study was conducted in two parts. First part consisted of six-item Dental Neglect Scale by using Dental Neglect Scale questionnaire with answers ranging from "Definitely no" to "Definitely yes", a five-point Likert scale, for each item and the scores for item three needs to be reversed for data analysis. The scores ranged from six to 30 with greater scores signifying higher dental neglect. Second part consisted of oral examination in which oral hygiene status was recorded using Oral Hygiene Index - Simplified ${ }^{6}$ as it easy to use, requires less time and helps in determining the status of oral hygiene in groups. Dental caries was recorded using Decayed Missing and Filled Teeth Index ${ }^{7}$ as it is a universally accepted index which gives a wider information on caries experience of a population. Mouth mirror, explorer and WHO probe was used for examination by a single, trained examiner.

The collected data were entered in Microsoft Excel Sheet and statistical analysis was done using IBM SPSS statistics for Windows, Version 20. Frequency distribution of responses to the six item scale was calculated along with mean scores for DNS. Level of statistical significance was set at $\mathrm{p}<0.05$. One-way ANOVA test was performed to see the difference of dental neglect scores in different age groups and with OHI-S while Independent t-test was used to compare mean DNS score with gender and groups classified based on DMFT scores.

\section{RESULTS}

Out of total 300 participants approached, 287 people participated in the study that is the non-response rate was $4.33 \%$ and there was no difference between participants who wished and refused to study. Mean age of the participants was 32.23 years (standard deviation $=12.43$ and range $=18$ 75). The mean DNS score was found to be 18.40 (standard deviation $=3.77$ and range $=9-27$ ). Table 1 shows distribution of study participants based on their socio-demographic variables and their relationship with mean DNS score. Statistically significant difference was seen between age of the participants and mean DNS score (P value $=0.033$ ) as well as with gender and mean DNS score (P value $=0.001$ ).

Table 2 shows the responses of the participants to the six items of the dental neglect scale. Majority of the participants agree to keeping up with their home dental care (43.9\%), receiving dental care as they should (43.9\%), needing dental care but putting it off (32.8\%), brushing as well as they

Table 1: Distribution of study groups according to age group and gender.

\begin{tabular}{|l|c|c|c|}
\multicolumn{1}{|c|}{ Sociodemographic variables } & Number of study subjects n(\%) & Mean DNS score (SD) & P value \\
\hline Age in years & & & \\
\hline $18-24$ & $78(27.2)$ & $18.97(4.10)$ & $18.48(3.68)$ \\
\hline $25-44$ & $165(57.5)$ & $17.48(3.42)$ & $0.033^{*}$ \\
\hline $45-64$ & $35(12.2)$ & $15.66(2.00)$ & \\
\hline$>65$ & $9(3.1)$ & & \\
\hline Total & $287(100)$ & $19.13(3.75)$ & $0.001^{\dagger}$ \\
\hline Gender & $146(50.9)$ & $17.65(3.66)$ & \\
\hline Male & $141(49.1)$ & & \\
\hline Female & $287(100)$ & & \\
\hline Total & & & \\
\hline
\end{tabular}

ANOVA test used, * signifies $\mathrm{P}$ value $<0.05$

Independent t-test used, ${ }^{\dagger}$ signifies $\mathrm{P}$ value $<0.05$ 
Table 2: Frequency distribution of dental neglect scale item response.

\begin{tabular}{|l|c|c|c|c|c|c|}
\hline \multicolumn{1}{|c|}{ DNS Scale } & $\begin{array}{c}\text { Strongly } \\
\text { disagree } \\
\mathbf{n ~ ( \% )}\end{array}$ & $\begin{array}{c}\text { Disagree } \\
\mathbf{n}(\mathbf{\%})\end{array}$ & $\begin{array}{c}\text { Neither agree } \\
\text { nor disagree } \\
\mathbf{n}(\mathbf{\%})\end{array}$ & $\begin{array}{c}\text { Agree } \\
\mathbf{n} \text { (\%) }\end{array}$ & $\begin{array}{c}\text { Strongly } \\
\text { agree } \\
\mathbf{n}(\mathbf{\%})\end{array}$ & $\begin{array}{c}\text { Mean } \\
\text { (SD) }\end{array}$ \\
\hline I keep up my home dental care & $28(9.8)$ & $45(15.7)$ & $76(26.5)$ & $126(43.9)$ & $12(4.2)$ & $3.17(1.06)$ \\
\hline I receive the dental care I should & $25(8.7)$ & $67(23.3)$ & $65(22.6)$ & $126(43.9)$ & $4(1.4)$ & $3.06(1.03)$ \\
\hline I need dental care but I put it off & $15(5.2)$ & $94(32.8)$ & $80(27.9)$ & $94(32.8)$ & $4(1.4)$ & $2.92(0.95)$ \\
\hline I brush as well as I should & $18(6.3)$ & $31(10.8)$ & $75(26.1)$ & $151(52.6)$ & $12(4.2)$ & $3.38(0.95)$ \\
\hline I control snacking between meals as well as I should & $44(15.3)$ & $130(45.3)$ & $73(25.4)$ & $40(13.9)$ & $0(0.0)$ & $2.38(0.90)$ \\
\hline I consider my dental health to be important & $15(5.2)$ & $33(11.5)$ & $45(15.7)$ & $182(63.4)$ & $12(4.2)$ & $3.50(0.93)$ \\
\hline
\end{tabular}

Table 3: Association of dental neglect score and Decayed Missing Filled Teeth index categorised.

\begin{tabular}{|c|c|c|c|}
\hline DMFT & Number of study subjects n(\%) & Mean DNS score (SD) & P value \\
\hline$\leq 3$ & $173(60.3)$ & $17.78(3.71)$ & \multirow{2}{*}{$0.022^{\dagger}$} \\
\hline$>3$ & $114(39.7)$ & $18.82(3.76)$ & \\
\hline Total & $287(100)$ & $18.40(3.7)$ & \\
\hline
\end{tabular}

Independent t-test used, ${ }^{\dagger}$ signifies $\mathrm{P}$ value $<0.05$

Table 4: Association of dental neglect score with OHI-S.

\begin{tabular}{|c|c|c|c|}
\hline OHI-S & Number of study subjects n(\%) & Mean DNS score (SD) & P value \\
\hline Good & $97(33.8)$ & $17.27(4.7)$ & \multirow{2}{*}{$0.001 *$} \\
\hline Fair & $175(60.9)$ & $18.93(3.1)$ & \\
\hline Poor & $15(5.3)$ & $19.60(2.5)$ & \\
\hline Total & $287(100)$ & $18.40(3.7)$ & \\
\hline
\end{tabular}

ANOVA test used, * signifies $P$ value $<0.05$

should (52.6\%) and considering dental health to be important (63.4\%). However, majority of the participants $45.3 \%$ disagree that they control snacking between meals as well as they should.

Table 3 shows the association of dental neglect score and categories based on DMFT scores that is $\leq 3$ and $>3$. Independent t-test was used and statistically significant difference was found in the dental neglect score between the groups(P value=0.022).

Table 4 shows the association of dental neglect score and OHI-S. ANOVA test was used which showed statistically significant difference between the dental neglect score and OHI-S (P value $=0.001$ )

\section{DISCUSSION}

Dental neglect scale measures the behavioral aspects of the individuals as the first four items of the scale look for information on self-care and professional dental care behavior. ${ }^{4}$ The last item measured the global rating of the importance placed upon dental health. ${ }^{8}$

The mean dental neglect score for this population was found to be 18.40 . However, they were higher than those reported by Ajagannanavar et al. ${ }^{9}$ in India that is 10.18 , Cooligde et al. ${ }^{2}$ in Seattle-Tacoma area that is 13.2 , McGrath et al. ${ }^{8}$ in Hong
Kong that is 14.81 and Jamieson and Thomson ${ }^{10}$ in Dunedin, New Zealand that is 12.4. In developing countries like Nepal, oral health needs are treated as secondary compared to general health needs due to various reasons like lack of awareness, high cost of the treatment, lack of insurance and inaccessibility which could be the reason for the higher dental neglect. They neglect in seeking preventive dental care leading to the increase in many dental diseases and people often visit the hospital when these unattended diseases cause pain and suffering.

Significant DNS score differences were found related to gender where mean score was slightly better than males i.e. $49 \%$. Similar findings were found in a other studies ${ }^{9}$ but were in contrast to other studies ${ }^{2,8}$ where no gender difference was found with respect to mean DNS score.

Statistically significant difference was found between DNS score and age similar to other studies. ${ }^{8,9}$ Further studies comparing various age group may be needed for better understanding of the association between age group and dental neglect. Mean neglect score was found to be more among the active working group of people which could be because they prioritise other things in life before dental care and with advancing age due to financial security and time, dental is given attention by them. 
Sarkar et al. ${ }^{5}$ divided the participants into two groups based on DNS scores ( $\leq 15$ and $>15)$ and found no statistically significant difference between DNS scores and groups based on DMFT scores while significant association was seen between DNS score and OHI-S. Study by Ajagannanavas et al. ${ }^{9}$ show that high positive correlation exists between dental neglect and dental caries and OHI. Our study shows statistically significant association between dental neglect scores and group categorised based on DMFT and OHI-S. Lack of proper diet, inadequate attention to oral hygiene regimen, waiting for dental problems to worsen before visiting the dentist, giving less importance to oral health along with many longstanding social, economic and educational barriers causing dental neglect leads to poor oral hygiene and many dental problems like caries. ${ }^{11}$

It would be of great use to know the factors that might contribute to dentally neglectful behavior as well as the effects such behavior have on oral health. Further studies can be carried out to find out if the scores reduce as a result of any oral health promotional programs to reduce dental neglect. As this is one of the first studies in Nepal to assess dental neglect among adults, further research could include the various social determinants of health like education, income, childhood experiences, accessibility to health care etc.

However, there are limitations in our study. The first one being the use of convenience sampling technique due to which the results may not be generalizable. The study participants could have been chosen from the community survey rather than hospital to make it more representative. Secondly, use of DMFT index doesn't specify the dental surfaces affected and doesn't show whether dental caries is active or arrested. Also, other social determinants like income, occupation and accessibility to health care could have been added.

\section{CONCLUSION}

The mean dental neglect score was found to be high among the study participants with variation among the age groups and gender. Dental caries status and oral hygiene status varied based on the dental neglect. Patients need to be counseled and motivated about their oral health.

\section{Clinical implications}

Patients need to be counselled and motivated about their oral health. As prevention poses less financial burden than treatment when the disease has progressed, oral health promotional programs need to be promoted to increase the knowledge, understanding and practices to improve oral health.

\section{ACKNOWLEDGEMENTS}

We would like to acknowledge all the participants in the study for their cooperation and support.

\section{Conflict of interest: None.}

\section{REFERENCES}

1. Skaret E, Astrom A, Haugejorden O, Klock K, Trovik T. Assessment of the reliability and validity of the Dental Neglect Scale in Norwegian adults. Community Dent Health. 2007;24(4):247-52.

2. Coolidge T, Heima M, Johnson EK, Weinstein P. The Dental Neglect Scale in adolescents. BMC Oral Health. 2009;9(1):1-7.

3. Thomson WM, Locker D. Dental neglect and dental health among 26-year-olds in the Dunedin Multidisciplinary Health and Development Study. Community Dent Oral Epidemiol. 2000;28(6):414-8.

4. Thomson WM, Spencer AJ, Gaughwin A. Testing a child dental neglect scale in South Australia. Community Dent Oral Epidemiol. 1996;24(5):351-6.

5. Sarkar P, Dasar P, Nagarajappa S, Mishra P, Kumar S, Balsaraf S, et al. Impact of dental neglect scale on oral health status among different professionals in Indore city-A cross- sectional study. J Clin Diagnostic Res. 2015;9(10):67-70.

6. Greene JC, Vermillion JR. The Simplified Oral Hygiene Index. J Am Dent Assoc. 1964;68(1):7-13.

7. World Health Organization. Oral Health Survey-Basic method 5th ed. Geneva, Switzerland: WHO. 2013.

8. McGrath C, Sham ASK, Ho DKL, Wong JHL. The impact of dental neglect on oral health: A population based study in Hong Kong. Int Dent J. 2007;57(1):3-8.

9. Ajagannanavar S, Sequeira P, Jain J, Battur H. Dental neglect among college going adolescents in Virajpet, India. J Indian Assoc Public Heal Dent. 2014;12(3):215-8.

10. Jamieson LM, Thomson M. Dental health, dental neglect, and use of services in an adult Dunedin population sample. N Z Dent J. 2002;98(431):4-8.

11. Ramazani N. Child Dental Neglect : A Short Review. Int J high risk Behav Addict. 2014;3(4). 